\title{
Clarifying the Strengths-Oriented Attitude among Nurses in Psychiatric Hospitals in Japan
}

\author{
Mika Kataoka1 $^{1 *}$, Kazuhiro Ozawa ${ }^{2}$, Tetsuya Tanioka1, Rozzano Locsin ${ }^{1}$ \\ ${ }^{1}$ Department of Nursing, Institute of Biomedical Sciences, Tokushima University Graduate School, Tokushima, \\ Japan \\ ${ }^{2}$ Gifu College of Nursing, Gifu, Japan \\ Email: ${ }^{*}$ mika3@tokushima-u.ac.jp
}

Received 23 May 2015; accepted 26 June 2015; published 29 June 2015

Copyright (C) 2015 by authors and Scientific Research Publishing Inc.

This work is licensed under the Creative Commons Attribution International License (CC BY). http://creativecommons.org/licenses/by/4.0/

(c) (†) Open Access

\section{Abstract}

Japanese psychiatric mental health systems are being steadily improved. Psychiatric nurses' attitude towards strengths of persons with mental disability is critical in order to promote de-institutionalization of patients. However, nurses' attitudes, particularly their Strengths-Oriented Attitude (SOA) has not been well studied and explained. The purpose of this study was to clarify the SOA of nurses working in psychiatric hospitals in Japan. There were 1148 Psychiatric Registered Nurses (PRN) and Psychiatric Practical Nurses (PPN) employed at 17 psychiatric hospitals in Japan who consented to participate in the study. The self-administered questionnaire was mailed and returned between October 2013 and January 2014. The subjects' SOA was evaluated using the Strengths-Oriented Attitude Inventory (SOAI) developed by the authors based on the work by Rapp and Goscha. The actual SOA and its relationship to individual characteristics were also analyzed to clarify the SOAI. Factor analysis revealed four components of the SOAI: Factor 1 = "Nursing practice based on the assessment which focused on social resources"; Factor $2=$ "Nursing practice based on the holistic assessment of person with mental disability"; Factor 3 = "Support in community which respected the person's way of living"; and Factor $4=$ "Emphasize of the strengths of individual with mental disability." Results indicated a high orientation toward Factors 2 and 4, but a low orientation toward Factors 1 and 3 . There were no significant differences between age, years of psychiatric nursing experience, academic background, and subjects' SOA. However, differences were observed in gender, current workplace, work position, type of license, and work experience. The subjects showed low orientation toward social resources and respected the patient's way of life. Nurses working in psychiatric mental health institutions should receive continuing education courses designed to increase their orientation toward Factors 1 and 3.

\footnotetext{
${ }^{*}$ Corresponding author.
} 


\section{Keywords}

\section{De-Institutionalization, Strengths-Oriented Attitude, Psychiatric Nurses, Japan}

\section{Introduction}

Since the beginning of the health care de-institutionalization movement in the mid-1950s, the role of psychiatric hospitals has changed [1]. In the United States and the United Kingdom, many long-stay patients have been discharged from psychiatric hospitals [2] [3]. Psychiatric services in western countries have shifted from being institutionally-based psychiatric-hospital to community-based care institutions [4]-[7]. Nevertheless, inpatient psychiatric-hospital services remain an essential type of care in modern psychiatry because community care may not be suitable for all patients, especially those with acute mental illness and those who lack support [8].

Along with changes in psychiatric medicine, the focus has turned from the traditional medical model emphasizing the problems and deficiencies of persons with mental disability to one that highlights the importance of person's strengths, abilities, and resources [9]-[11]. Investigative research on the effects of strengths-based approaches and strength models has also been conducted [10] [12]. However, the findings are inconclusive, and further evidence is required to ascertain the impact of this approach on mental-health care.

Until recently, psychiatric health care in Japan was characterized by a paucity of physician and nursing personnel and the largest number of psychiatric-ward beds worldwide [13]. Bias from local residents and insufficient community services had led to extended stays in psychiatric hospitals [14]. However, in 2013, the Japanese Ministry of Health, Labor, and Welfare identified psychiatric diseases as one of “Japan's 5 major diseases” and launched a high-priority policy that involved the general citizenry in these diseases [15]. Based on the mental health policy "A Vision for Reform of the Mental Health Care System (2004)" [16], mental-health services in Japan have been transitioning from hospital-centered care to care in which the patients live in the community. Moreover, the "Committee Report on Future Mental Health and Welfare (2009)" [17] and "Investigatory Team for Building a New Community Psychiatric Health Care System (2010)" called for changes in the roles and functions of psychiatric hospitals. Although Japan has lagged behind other countries, psychiatric medicine has started moving toward de-institutionalization [18] [19].

In 2008, the total number of psychiatric hospitals in Japan was 1637 hospitals, and this number was reduced to 1622 hospitals in 2012 . There were 27.2 psychiatric beds per 10,000 persons in 2008 , and this average was reduced to 26.5 in 2012. The average length of stay in psychiatric hospitals in 2008 was 313 days, and in 2012 was 292 days [20]. This evidence shows that the Japanese psychiatric mental health systems are being steadilyimproved.

Progress towards de-institutionalization requires both the promotion of team medical care [21] [22] and significant effort by the roughly 110,000 Psychiatric Registered Nurses (PRN) and Psychiatric Practical Nurses (PPN) working in Japan's psychiatric hospitals. To fulfill this role, nurses need to have both an attitude and orientation that can serve as bases for their actions and training in providing community care.

The nurse theorist Peplau [23] described nurses' functions as providing "assistance in the identification of problematic situations and appreciating and liberating the positive forces in patient personalities.”

Clinically, data that represent patients' strengths can be important knowledge for nurses [24]. As part of the nursing diagnostic process, nurses are to assess the strengths and resources of the patient and understand them. It is also important for nurses to use those strengths and resources to the patient's advantage when providing care [25] [26]. These strengths can assist nurses' to intervene so as to reduce or prevent patients' problems in another health-related area [24].

Recently, strengths-based nursing care has been introduced as a new paradigm for nursing and health care [27]. One study analyzed inner-strength [28] based on an approach that emphasized a person's health and well-being over the cause of the disease [29]. However, it has been shown that if patients depend on their families or other care providers, it is difficult to assess their true inner strengths [28]. A scale has been developed based on this perspective [30], and studies [31] [32] have been conducted in areas such as the relationship of inner-strength with health in elderly people and with depression in elderly women [33].

In Japan, a concept analyses of strength [34] using qualitative research methods was performed, and the ap- 
plication of strengths in the process of lifestyle changes was also studied [35] [36]. In the field of psychiatric nursing, there were studies on care provided by psychiatric nurses to improve the strengths of patients with eating disorders [37] and on ways of grasping the strengths of patients in acute-care wards [38]. Studies have shown the importance of focusing on strengths rather than deficits in livelihood support groups in the community [9]. It is important for psychiatric nurses to possess an attitude oriented towards knowing and assessing the strengths of persons with mental disability. However, the state of nurses' Strengths-Oriented Attitude (SOA) has yet to be clarified and explained. The Strengths-Oriented Attitude Inventory (SOAI) based on the work of Rapp and Goscha [39] was developed in order to evaluate psychiatric nurses' SOA.

The purpose of this study was to clarify the strengths-oriented attitude of nurses working in psychiatric hospitals in Japan.

\section{Methods}

\subsection{Subjects}

The subjects of this survey were 1148 PRN and PPN employed at 17 psychiatric hospitals in Japan whose consent had been obtained. The data were collected from October 2013 to January 2014. Psychiatric nurses who had agreed to participate in the survey were mailed survey-request documents describing the study and survey forms. Responses were obtained using a self-administered, anonymous form. The subjects completed questionnaire items assessing baseline demographic data and the SOA.

\subsection{Instruments}

Individual characteristics, such as gender, age, years worked, workplace, work position, type of license, academic background, work experience, and psychiatric-care experience were surveyed. The subjects' SOA was evaluated using the SOAI. The SOAI was developed by us authors based on the work of Rapp and Goscha [39] in the United States. The subjects rated each item on a Likert 4 point agree/disagree scale: strongly disagree (1), disagree (2), agree (3) or strongly agree (4). In the SOAI, "strengths" is defined as the strengths, abilities, and resources of a person with a mental disability. The SOA of the PRN and PPN refers to an attitude that indicates possession of thoughts and feelings related to understanding and appreciating the strengths and abilities of a person with a mental disability. Furthermore, these factors should be reflected in nursing practice. The demographic information of the subjects was reported by frequency analyses.

\subsubsection{Reliability Analysis of the SOAI}

Cronbach's alpha coefficient correlation and an exploratory factor analysis were used for evaluating the SOAI. A rotation of factor loadings was conducted using the Equamax Method. Kaiser-Meyer-Olkin and the Bartlett's test of Sphericity were used to assess the validity of the SOAI. The number of factors were decided by the Kaiser criterion, and factor loadings of less than 0.40 were omitted to improve clarity.

\subsubsection{Overall Analysis of the SOAI}

To obtain an overall picture of the SOAI, the mean SOAI total score and mean factor points (MFP) for each subscale were calculated. The total score and each MFP were categorized every 0.5 point to create frequency distributions.

\subsubsection{Attribute-Comparison Testing}

The actual state of the SOA and its relationships to individual characteristics were analyzed. Pearson correlations were calculated to assess associations between the mean SOAI total score, MFP, age, and years of psychiatric nursing experience. A correlation was defined as evident when the coefficient was 0.4 or higher.

The relationships between individual characteristics, the mean SOAI total score, and each MFP were analyzed. Groups were created based on gender, workplace, work position, work experience, psychiatric-care experience, and experience in other departments. Homoscedasticity was tested with Levene's test followed by either Welch's t-test or Student's t-test. In addition, the relationships between SOAI, type of license, and academic background were analyzed. Data were analyzed using analysis of variance (ANOVA) and post-hoc tests of latent classes, multiple comparisons, and Tukey's honest significant difference (HSD) test. Missing value was excluded from each data analysis. For all analyses, the statistical-significance level was 0.05 . All statistical analyses were per- 
formed using the SPSS for Windows software (version 20.0; SPSS Inc., Chicago, IL).

\subsection{Ethical Considerations}

This research was approved by the University of Tokushima Hospital Clinical Study Ethical Review Board (approval number: 1201). No harm to the subjects could be identified. Return of the survey implied that the subjects gave consent. The subjects were notified that privacy would be protected; only aggregate data are used in reporting the findings.

\section{Results}

\subsection{Demographic Data}

The subjects were 1148 PRN and PPN in Japan; 1055 surveys were returned (response rate $=91.9 \%$ ). Due to incomplete returns of the SOAI, data from only 984 subjects were analyzed: mean age $=44.7 \pm 11.0$ (range $=$ 20 - 70; $\mathrm{n}=961$ ) years; 315 men (32.0\%) and 669 women (68.0\%); 643 PRN (65.3\%) and 341 PPN (34.7\%). They had $13.8 \pm 9.2$ (range $0.0-43.0 ; n=966$ ) years of experience in psychiatric departments. There were 533 subjects $(54.2 \%)$ with experience in other departments (mean $=8.8 \pm 7.6$ years; range $=0.3-37.0 ; \mathrm{n}=496$ ). Finally, the subjects had $18.2 \pm 10.4$ years (range $=0.0-47.0 ; n=936$ ) of nursing experience.

\subsection{SOAI Reliability Analysis}

Rapp and Goscha identified six principles and strengths assessments, its principle, namely: (1) "People with psychiatric disabilities can recover, reclaim, and transform their lives". (2) "The focus is on individual strengths rather than deficits". (3) "The community is viewed as an oasis of resources". (4) "The client is the director of the helping process". (5) "The case manager-client relationship is primary and essential". (6) "The primary setting for the work is the community”. Strengths assessment is organized in seven life domains, namely; Daily living, Finances, Work/education, Social network, Recreation, Overall health, and Spirituality [39].

Result of the exploratory factor analysis, among the six principles and strengths assessments, all strengths assessments items were included, but Principle (1) was excluded by factor loadings of less than 0.40. A relation between "principles and strengths assessments" and the SOAI is indicated: Principle (2), and SOAI items 4 and 5; Principle (3) and (6), and item 8 of SOAI; Principle (4), with item 6 of SOAI; Principle (5), and item 7 of SOAI. In the strengths assessments: Daily living was related to items 18 and 20 of SOAI; Finances with item 22 of SOAI; Work/education with item 23 of SOAI; Social network with items 15, 19 and 21 of SOAI; Recreation with item 24 of SOAI; Overall health, was related with items 10, 16 and 17 of SOAI; and Spirituality with item 9.

As shown in Table 1, analysis of the SOAI factors extracted four components from 22 items. Initial items were 25 , three items' $(1,2$ and 3 ) factor loading was less than 0.4 , those were removed.

The Kaiser-Meyer-Olkin value was 0.925 , and the Bartlett's test of Sphericity was significant at $P<0.001$. The factor analysis revealed four components of the SOA: Factor 1 = "Nursing practice based on the assessment which focused on social resources," Factor 2 = "Nursing practice based on the holistic assessment of person with mental disability," Factor 3 = "Support in community which respected the person's way of living," and Factor 4 = "Emphasize of the strengths of individual with mental disability," The resulting scales had an internal consistency (Cronbach's alpha) of $0.872,0.876,0.825$, and 0.788 , respectively, and the total scale had an internal consistency of 0.903 , accounting for a total of $50.7 \%$ of the variance.

\subsection{Overall Analysis of the SOAI}

Table 2 shows the means, standard deviations, and frequency distributions of the mean SOAI total score and each subscale score. Factors 2 and 4 had ratios higher than 3.0, and the MFP scores were $82.9 \%$ and 93.6\%, respectively.

\subsection{Attribute Comparison Testing}

3.4.1. Correlations between the SOAI, Age, and Years of Psychiatric Nursing Experience

Table 3 shows that there were no correlations between the mean SOAI total score, the MFP scores, age, and years of experience as psychiatric nurses. 
Table 1. Exploratory factor analysis of the strengths oriented attitude inventory.

Items
Factor loadings

Factor 1 Factor 2 Factor 3 Factor 4

Factor 1: Nursing practice based on the assessment which focused on social resources.

23 Nurses assess persons with mental disability and provide care with emphasis on current job or schoolwork.

20 Nurses assess mentally disabled person and provides care with emphasis on his/her housing.

22 Nurses assess persons with mental disability and provide care with emphasis on his/her economic situation including insurance.

25 Nurses assess persons with mental disability and provide care with emphasis on necessary social resource.

24 Nurses assess persons with mental disability and provide care with emphasis on his/her hope.

21 Nurses assess persons with mental disability and provide care with emphasis on his/her 21 human relations.

Factor 2: Nursing practice based on the holistic assessment of person with mental disability.

17 Nurses assess persons with mental disability and provide care with emphasis on mental health conditions.

18 Nurses assess persons with mental disability and provide care with emphasis on ability to perform activities of daily life.

16 Nurses assess persons with mental disability and provide care with emphasis on physical conditions.

19 Nurses assess persons with mental disability and provide care with emphasis on social ability.

Factor 3: Support in community which respected the person's way of living.

9 Behaviors of person with mental disability is affected by their own life histories, current social relationships, and goals in life.

10 The nurses' role is to maintain a healthy lifestyle for each person.

8 The main place of supporting persons with mental disability is a community.

15 The availability of peer support is important for person with mental disability.

Knowing a person's inner world, intentionally leads to a nursing intervention illustrating

12 the person's ways of living to maintain and improve the person's quality of living in the community

11 Nurse have to improve patient's ability to do self-management and self-care.

13 The innovations of the functional capabilities of psychiatric hospitals are required for deinstitutionalization.

6 In the process of providing care, persons with mental disability is a decision maker.

14 Different care providers have different appreciation for providing care for mentally disabled persons, and the difference is important for team care.

Factor 4: Emphasize on the strengths of individuals with mental disability.

To achieve recovery that is desired by a person with mental disability, nurses have to care

5 for them by bringing out their own abilities with help from health care and welfare specialists, family members, and community.

4 It is important to support persons with mental disability so that they can bring up their own ability that they already have.

7 In the care process, the human relationship between nurse and nursed is fundamental.

Eigen value

Variance, \%

Cumulative variance, \%

Cronbach's alpha

\begin{tabular}{l|lll}
0.768 & 0.143 & 0.026 & 0.023 \\
0.765 & 0.276 & 0.069 & -0.007 \\
0.661 & 0.323 & 0.081 & 0.074 \\
0.585 & 0.403 & 0.169 & 0.146 \\
0.534 & 0.360 & 0.174 & 0.151 \\
0.529 & 0.489 & 0.155 & 0.082
\end{tabular}

0.203

0.823

0.120

0.172

0.342

0.713

0.138

0.333

0.654

0.086

0.067

0.466

0.639

$0.144 \quad 0.081$

0.058

0.141

0.553

0.308

0.049

0.110

0.532

0.316

0.154

0.013

0.532

0.214

0.162

0.209

0.527

0.233

0.071

0.111

0.518

0.434

0.048

0.194

0.487

0.335

0.057

0.145

0.476

0.331

0.175

0.096

0.413

0.288

0.113

0.153

0.408

0.147

0.035

0.101

0.179

0.797

0.061

0.116

0.262

0.728

0.039

0.098

0.449

0.523

3.120

2.966

2.677

2.382

14.181

13.482

12.169

10.827

14.181

27.663

39.831

50.659

0.872

$0.825 \quad 0.788$

Notes: Cronbach's alpha coefficient $(\alpha)$ for the total score was 0.903 . A number of left italics is the question number. Initial items were 25, three items' (1, 2 and 3 ) factor loading was less than 0.4 , those were removed. 
Table 2. Means, standard deviations and frequency distributions of the strengths oriented attitude inventory.

\begin{tabular}{rccccccccccc}
\hline & \multicolumn{10}{c}{$\mathrm{n}(\%)$} \\
\hline & Mean & (SD) & point & $1.00-1.49$ & $1.50-1.99$ & $2.00-2.49$ & $2.50-2.99$ & $3.00-3.49$ & $3.50-3.99$ & 4.00 \\
\hline SOAI total score & 2.98 & $(0.28)$ & $0(0)$ & $1(0.1)$ & $33(3.4)$ & $438(44.5)$ & $458(46.5)$ & $49(5.0)$ & $5(0.5)$ \\
Factor 1 & 2.81 & $(0.41)$ & $5(0.5)$ & $8(0.8)$ & $152(15.4)$ & $260(26.4)$ & $515(52.3)$ & $29(2.9)$ & $15(1.5)$ \\
Factor 2 & 2.98 & $(0.37)$ & $5(0.5)$ & $1(0.1)$ & $43(4.4)$ & $119(12.1)$ & $733(74.5)$ & $39(4.0)$ & $44(4.5)$ \\
Factor 3 & 3.02 & $(0.31)$ & $0(0)$ & $0(0)$ & $32(3.3)$ & $336(34.1)$ & $535(54.4)$ & $63(6.4)$ & $18(1.8)$ \\
Factor 4 & 3.20 & $(0.40)$ & $1(0.1)$ & $0(0)$ & $13(1.3)$ & $49(5.0)$ & $699(71.0)$ & $106(10.8)$ & $116(11.8)$ \\
\hline
\end{tabular}

Abbreviations: SD = standard deviations, Factor 1, Nursing practice based on the assessment which focused on social resources; Factor 2, Nursing practice based on the holistic assessment of person with mental disability; Factor 3, Support in community which respected the person's way of living; Factor 4, Emphasize of the strengths of individual with mental disability.

Table 3. Pearson correlation coefficients between the SOAI, age, and years of experience as psychiatric nurses.

\begin{tabular}{ccccccc}
\hline & $\mathrm{n}$ & SOAI total score & Factor 1 & Factor 2 & Factor 3 & Factor 4 \\
\hline Age & 961 & -0.123 & -0.036 & -0.062 & -0.156 & -0.107 \\
Psychiatric nursing experience & 966 & -0.051 & 0.005 & -0.023 & -0.086 & -0.038 \\
Nursing experience & 936 & -0.085 & -0.025 & -0.048 & -0.108 & -0.070 \\
\hline
\end{tabular}

Abbreviations: SOAI, Strengths Oriented Attitude Inventory; Factor 1, Nursing practice based on the assessment which focused on social resources; Factor 2, Nursing practice based on the holistic assessment of person with mental disability; Factor 3, Support in community which respected the person's way of living; Factor 4, Emphasize of the strengths of individual with mental disability.

\subsubsection{The Relationship between the SOAI, Gender, Workplace, Work Position, Type of License, and Academic Background}

Table 4 shows that there were significant differences between gender, workplace, work position, type of license, the SOAI total score, and MFP. Men scored significantly more MFP of Factor $3(P=0.049)$. The mean SOAI total score $(P=0.003)$ and the number of MFP of Factors $1(P=0.007)$ and $3(P=0.007)$ were significantly higher for those who were working in the community than those who were working in hospital wards.

The mean SOAI total score $(P=0.005)$ and the number of MFP of Factors $3(P=0.007)$ and $4(P<0.001)$ were significantly higher for managers than staff. The mean SOAI total score $(P<0.001)$ and the number of MFP of Factors $2(P=0.001), 3(P<0.001)$, and $4(P<0.001)$ were significantly lower for those who had a practice nurse $(\mathrm{PN})$ license than those who had a registered nurse $(\mathrm{RN})$ license or both a $\mathrm{RN}$ and PN license.

\subsubsection{The Relationship between the SOAI, Work Experience, and Psychiatric-Care Experience}

The subjects' had varied psychiatric-work experience. For example, 84 nurses (8.5\%) had experience in homevisit nursing, 75 (7.6\%) in day-care nursing, 257 (26.1\%) in physical-complication wards, $682(69.3 \%)$ in acute wards, 863 (87.7\%) in chronic wards, and $152(15.4 \%)$ in outpatient wards. In addition, the content of the subjects' psychiatric-care experience differed; 91 (9.2\%) had psycho-education, 251 (25.5\%) had discharge facilitation, 326 (33.1\%) had Social Skills Training (SST), and 25 (2.5\%) had team approaches.

There were significant differences between work experience, psychiatric-care experience, and the SOAI score, as shown in Table 5. The mean SOAI total score $(P=0.005)$ and the number of MFP of Factors $3(P<0.001), 4$ $(P=0.004)$ were significantly higher for those who had experience in home-visit nursing than those who did not. The mean SOAI total score $(P=0.029)$ and the number of MFP of Factor $3(P=0.011)$ was significantly higher for those who had experience in day-care nursing than that who did not, and the number of MFP of Factor $1(P=$ 0.015) was significantly lower for those who had experience in physical-complication wards than those who did not. Finally, the number of MFP of Factor $4(P=0.022)$ was significantly higher for those who had experience in acute wards than those who did not.

The mean SOAI total score $(P<0.001)$ and the number of MFP of Factors $1(P=0.001), 2(P=0.007), 3(P$ $=0.001)$, and $4(P=0.004)$ were significantly higher for those who had experience in psycho-education than those who did not. The mean SOAI total score $(P=0.002)$ and the number of MFP of Factors $1(P=0.014)$, 
Table 4. The relationship between the SOAI, gender, workplace, work position, type of license, and academic background.

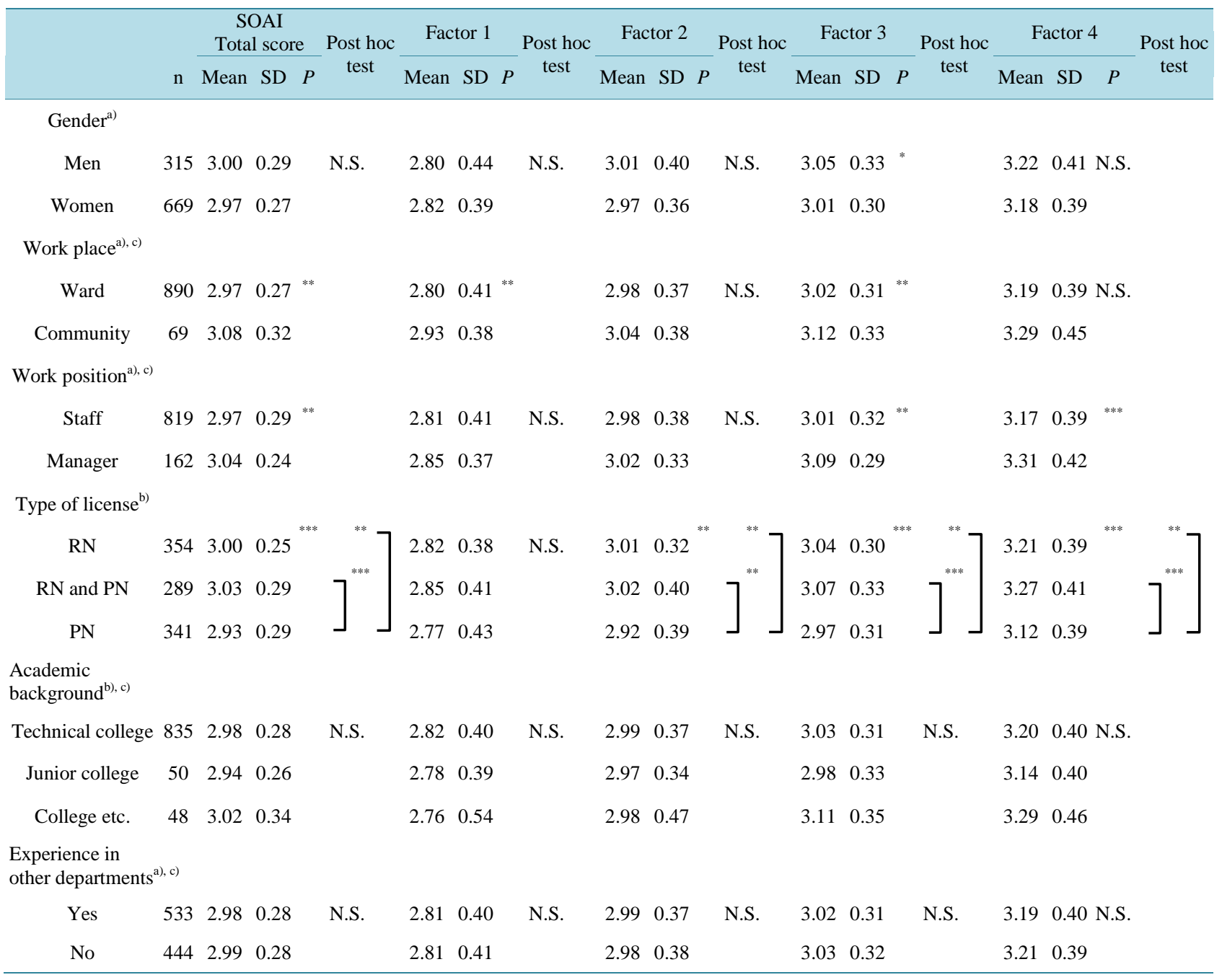

Notes: ${ }^{*} P<0.05,{ }^{* *} P<0.01,{ }^{* * *} P<0.001,{ }^{a)}$ Welch's t-test or Student's t-test, ${ }^{\text {b) }}$ ANOVA with Tukey's HSD test, and ${ }^{\text {c) }}$ Others and unknown data were omitted from the data analysis. Abbreviations: N.S. = Not Significant, ANOVA = analysis of variance; SD = standard deviations; SOAI, Strengths Oriented Attitude Inventory; RN, Registered Nurse; PN, Practicical Nurse; College etc., college and graduate school. Factor 1, Nursing practice based on the assessment which focused on social resources; Factor 2, Nursing practice based on the holistic assessment of person with mental disability; Factor 3, Support in community which respected the person's way of living; Factor 4, Emphasize of the strengths of individual with mental disability.

$2(P=0.018), 3(P=0.040)$, and $4(P=0.002)$ were significantly higher for those who had experience in discharge facilitation than those who did not.

The mean SOAI total score $(P=0.002)$ and the number of MFP of Factors $3(P=0.008)$ and $4(P<0.001)$ were significantly higher for those who had experience in SST than those who did not, and the SOAI total score $(P=0.002)$ and the number of MFP of Factor $1(P=0.019)$ and $2(P=0.007)$ were significantly higher for those who had experience in team approaches than those who did not.

\section{Discussion}

This study found no significant differences between academic background, experience in other departments, work experiences (chronic ward or outpatient), and SOAI score. There were no correlations between age, years of psychiatric nursing experience and SOAI score. However, differences were observed for gender, workplace, work position, type of license, work experience (home-visiting, day-care, physical complications) and psychiatric-care experience (psycho-education, discharge facilitation, SST, and team approach). Score in Factor 3 "Support in community which respected the person's way of living" was significantly higher among male Japanese 
Table 5. The relationship between the SOAI, work experience, and psychiatric-care experience.

\begin{tabular}{|c|c|c|c|c|c|c|c|c|c|c|c|c|c|c|c|c|c|}
\hline & & \multicolumn{4}{|c|}{ SOAI Total score } & \multicolumn{3}{|c|}{ Factor 1} & \multicolumn{3}{|c|}{ Factor 2} & \multicolumn{3}{|c|}{ Factor 3} & \multicolumn{3}{|c|}{ Factor 4} \\
\hline & & $\mathrm{n}$ & Mean & SD & $P$ & Mean & SD & $P$ & Mean & SD & $P$ & Mean & SD & $P$ & Mean & SD & $P$ \\
\hline \multicolumn{18}{|l|}{ Work experience } \\
\hline \multirow[t]{2}{*}{ Home-visiting } & Yes & 84 & 3.06 & 0.27 & ** & 2.87 & 0.41 & N.S. & 3.01 & 0.38 & N.S. & 3.14 & 0.31 & $* * *$ & 3.32 & 0.43 & $* *$ \\
\hline & No & 896 & 2.98 & 0.28 & & 2.81 & 0.41 & & 2.98 & 0.37 & & 3.01 & 0.31 & & 3.19 & 0.39 & \\
\hline \multirow[t]{2}{*}{ Day-care } & Yes & 75 & 3.05 & 0.28 & * & 2.90 & 0.37 & N.S. & 2.99 & 0.34 & N.S. & 3.11 & 0.32 & * & 3.25 & 0.41 & N.S \\
\hline & No & 905 & 2.98 & 0.28 & & 2.81 & 0.41 & & 2.98 & 0.37 & & 3.02 & 0.31 & & 3.19 & 0.40 & \\
\hline \multirow[t]{2}{*}{$\begin{array}{c}\text { Physical } \\
\text { complications }\end{array}$} & Yes & 257 & 2.96 & 0.28 & N.S. & 2.76 & 0.43 & * & 2.96 & 0.42 & N.S. & 3.01 & 0.30 & N.S. & 3.18 & 0.37 & N.S \\
\hline & No & 723 & 2.99 & 0.28 & & 2.83 & 0.40 & & 2.99 & 0.35 & & 3.03 & 0.32 & & 3.20 & 0.41 & \\
\hline \multirow[t]{2}{*}{ Acute ward } & Yes & 682 & 2.99 & 0.27 & N.S. & 2.82 & 0.40 & N.S. & 2.99 & 0.38 & N.S. & 3.03 & 0.31 & N.S. & 3.22 & 0.41 & $*$ \\
\hline & No & 298 & 2.97 & 0.29 & & 2.80 & 0.42 & & 2.97 & 0.36 & & 3.01 & 0.32 & & 3.15 & 0.37 & \\
\hline \multirow[t]{2}{*}{ Chronic ward } & Yes & 863 & 2.98 & 0.27 & N.S. & 2.81 & 0.40 & N.S. & 2.98 & 0.36 & N.S. & 3.02 & 0.32 & N.S. & 3.20 & 0.39 & N.S \\
\hline & No & 117 & 3.00 & 0.32 & & 2.83 & 0.47 & & 3.02 & 0.45 & & 3.04 & 0.31 & & 3.20 & 0.46 & \\
\hline \multirow[t]{2}{*}{ Outpatient } & Yes & 152 & 3.00 & 0.28 & N.S. & 2.84 & 0.40 & N.S. & 2.95 & 0.37 & N.S. & 3.05 & 0.31 & N.S. & 3.24 & 0.42 & N.S \\
\hline & No & 828 & 2.98 & 0.28 & & 2.81 & 0.41 & & 2.99 & 0.37 & & 3.02 & 0.32 & & 3.19 & 0.39 & \\
\hline \multicolumn{18}{|l|}{$\begin{array}{l}\text { Psychiatric-care } \\
\text { experience }\end{array}$} \\
\hline \multirow[t]{2}{*}{$\begin{array}{l}\text { Psycho- } \\
\text { education }\end{array}$} & Yes & 91 & 3.10 & 0.29 & $* * *$ & 2.94 & 0.37 & ** & 3.08 & 0.37 & ** & 3.14 & 0.36 & ** & 3.31 & 0.42 & ** \\
\hline & No & 893 & 2.97 & 0.28 & & 2.80 & 0.41 & & 2.97 & 0.37 & & 3.01 & 0.31 & & 3.18 & 0.39 & \\
\hline \multirow[t]{2}{*}{$\begin{array}{l}\text { Discharge } \\
\text { facilitation }\end{array}$} & Yes & 251 & 3.03 & 0.26 & ** & 2.87 & 0.39 & $*$ & 3.03 & 0.34 & * & 3.06 & 0.33 & * & 3.27 & 0.41 & $* *$ \\
\hline & No & 733 & 2.97 & 0.28 & & 2.79 & 0.41 & & 2.97 & 0.38 & & 3.01 & 0.31 & & 3.17 & 0.39 & \\
\hline \multirow[t]{2}{*}{$\begin{array}{l}\text { Social skills } \\
\text { training }\end{array}$} & Yes & 326 & 3.02 & 0.28 & ** & 2.84 & 0.42 & N.S. & 3.01 & 0.38 & N.S. & 3.06 & 0.32 & $* *$ & 3.27 & 0.40 & ${ }^{* * *}$ \\
\hline & No & 658 & 2.96 & 0.28 & & 2.80 & 0.40 & & 2.97 & 0.37 & & 3.01 & 0.31 & & 3.16 & 0.39 & \\
\hline \multirow[t]{2}{*}{ Team approach } & Yes & 25 & 3.15 & 0.34 & ** & 3.00 & 0.47 & * & 3.18 & 0.38 & ${ }^{* *}$ & 3.18 & 0.39 & N.S. & 3.32 & 0.40 & N.S \\
\hline & No & 939 & 2.98 & 0.28 & & 2.81 & 0.40 & & 2.98 & 0.37 & & 3.02 & 0.31 & & 3.19 & 0.40 & \\
\hline
\end{tabular}

Notes: ${ }^{*} P<0.05,{ }^{* *} P<0.01,{ }^{* * *} P<0.001$, N.S. = not significant. Welch's t-test or Student's t-test. Unknown data were omitted from the data analysis. Abbreviations: SD = standard deviations; SOAI, Strengths Oriented Attitude Inventory; Factor 1, Nursing practice based on the assessment which focused on social resources; Factor 2, Nursing practice based on the holistic assessment of person with mental disability; Factor 3, Support in community which respected the person's way of living; Factor 4, Emphasize of the strengths of individual with mental disability.

PRN and PPN than among female. Hence, it was thought need to conduct further study to confirm gender differences and relationship between subjects' backgrounds and SOA.

In addition, it appears to be not the length of experience that is important to the SOA of PRN and PPN, but kind of job component and experience they accumulated in clinical settings. Job components were significantly related to work position and licenses type of nurse.

For work positions, for the mean SOAI total scores and the number of MFP of Factors 3 and 4 were significantly higher for managers than staff. Compared with staff who have ample opportunities to interact with persons with mental disability in a one-to-one manner, managers are able to judge their strengths more calmly as a result of having had fewer such opportunities. Moreover, managers have more opportunities to work with other professionals and nurses in other wards [40] and are constantly thinking about discharging patients as part of their ward- and bed-management duties [41]. 
The mean SOAI total score and number of MFP of Factors 2, 3 and 4 were significantly lower for those who had a PN license than those who had an RN license or both RN and PN licenses. This indicates the influence of the curricula in nursing education. Specifically, PN education emphasizes the various views and personalities of sick people and their families. PNs are taught fundamental skills that enable the ethical practicing of nursing. In contrast, RN education emphasizes nurses' role in health maintenance and improvement, disease prevention, and health recovery. RNs learn fundamental skills that enable them to respond to different health conditions and changes in these conditions. RNs are also taught to understand their role in relation to that of other professionals in the health, medical, and welfare systems; they are also taught basic skills for cooperating and working with other professionals. As professionals, they practice basic skills that enable them to independently update their knowledge regarding the latest academic and technologic developments [42]. Thus, the different characteristics between PNs and RNs influences their strengths orientations.

There were significant differences observed regarding workplaces and psychiatric-care experience with respect to PRN and PPN. The SOAI total score and the number of MFP of Factors 1 and 3 were significantly higher for those who were working in the community than those who were working in hospital wards. PRN and PPN who were working in the community were collaborating with other professionals, such as public-health nurses and social workers. Thus, they were able to perform social-based assessments and provide communitybased lifestyle support.

Regarding different workplaces, the SOAI total score and the number of MFP of Factors 3 and 4 were significantly higher for those who had experience in home-visit nursing than those who did not, and the mean SOAI total score and the number of MFP of Factor 3 was significantly higher for those who had experience in day-care nursing than those who did not. However, there was no significant difference based on outpatient experience. Home-visit and day-care nurses provided support at locations that were closer to their patients' residences than did outpatient nurses, and this experience appears to have affected their respective strengths-orientated attitudes.

Regarding psychiatric-care experience, PRN and PPN with psycho-education and discharge-facilitation experience had significantly higher scores on all items compared to those without such experience. Further, those who had experience in SST and team approaches had significantly higher SOAI total scores than those without these experiences. Because a strengths viewpoint is already included in these forms of support, developing them in actual practice may be linked to improving the strengths orientation of PRN and PPN.

The SOA among Japanese PRN and PPN showed a high orientation toward Factors 2 and 4, but a low orientation toward Factors 1 and 3 as assessed by frequency distribution. If nurses provided care with an emphasis on social resources and respect for the patient's way of living through multidisciplinary cooperation, it would likely increase the overall SOA by way of the nurses' professional experiences.

The results of this study indicate that two measures could help increase the SOA of PRN and PPN. The first is to reinforce education about Factors 1 ("Nursing practice based on the assessment which focused on social resources") and 3 ("Support in community which respected the person's way of living”) for PPN staff and working staff in hospital wards. The second is to strengthen staff-development systems and the variety of duty assignments so that PRN and PPN gain direct experience with psycho-education, discharge planning, and homevisit nursing.

Rapp and Goscha's "Strengths model” focused on the "strengths mode of practice, on helping people, not as patients or clients, but as individuals" [43]. Also, the intent of the model is to influence the practice of mental health professionals and practitioners such as those in social work, psychology, nursing, psychiatry, vocational rehabilitation, and occupational therapy, including those practicing as case managers. Also, their Strengths model focused on Resilience, Health and Wellness, Hope, and Positive psychology of persons with mental disability, rather than on the patient's problems, disability and/or illness. It is important, for PRN and PPN to have perspectives and SOA, in order for psychiatric care to progress towards de-institutionalization of persons with mental health disabilities. By utilizing scales such as the SOAI, it can illustrate effects, including the negative effect as a factor of nursing practice, and its effect on education. Perhaps a consideration of an on-the-job training for rehabilitation service.

The SOAI has limited reliability. As SOAI was developed by the researchers based on Rapp and Goscha's six principles and strengths assessments items, its psychometric testing is critical establishing its ability to predict SOA. With the Japanese sample, the study provides an initial investigation into its ability to predict outcomes in a particular focused group. The SOAI has not been studied in other countries with different practice processes of psychiatric management. It is envisioned to be tested soon. 
It is necessary to conduct further psychometric testing to increase the reliability and validity of the SOAI. Also, it will be necessary to compare psychiatric nurses' SOA using cross-national research considering culture and practice similarities and differences, to clarify inter-professional differences, and to examine the relationship between SOA and care abilities of psychiatric nurses.

\section{Conclusion}

The aim of this study was to clarify the SOA among PRN and PPN in psychiatric hospitals in Japan. These subjects showed a low orientation toward social resources and respected the patients' way of living. In addition, there were significant differences in the type of license, work position, work experience, and psychiatric-care experience. Nurses working in psychiatric support situations should receive continuing education designed to increase their orientation toward Factors 1 and 3.

\section{Acknowledgements}

We would like to express our deep gratitude to the Japanese psychiatric nurses who participated in this study, our family members, and academic supervisors. In particular, we appreciate clinicians: Dr. Kazushi Mifune, MD, $\mathrm{PhD}$ (Mifune Hospital) and Dr. Kanji Hikasa, MD, PhD, helping this study.

\section{Disclosure}

All of the authors declare that they have no direct conflicts of interest or grant support that is directly related to the content of the study.

\section{References}

[1] Scherl, D.J. and Macht, L.B. (1979) Deinstitutionalization in the Absence of Consensus. Hospital \& Community Psychiatry, 30, 599-604. http://dx.doi.org/10.1176/ps.30.9.599

[2] Boschma, G. (2011) Deinstitutionalization Reconsidered: Geographic and Demographic Changes in Mental Health Care in British Columbia and Alberta, 1950-1980. Histoire Sociale, 44, 223-256. http://dx.doi.org/10.1353/his.2011.0020

[3] Brown, P. and Smith, C.J. (1988) Mental Patients’ Rights: An Empirical Study of Variation across the United States. International Journal of Law and Psychiatry, 11, 157-165. http://dx.doi.org/10.1016/0160-2527(88)90028-3

[4] Jacob, K.S. (2001) Community Care for People with Mental Disorders in Developing Countries: Problems and Possible Solutions. British Journal of Psychiatry, 78, 296-298. http://dx.doi.org/10.1192/bjp.178.4.296

[5] Burti, L. (2001) Italian Psychiatric Reform 20 plus Years after. Acta Psychiatrica Scandinavica Supplementum, 410, 41-46. http://dx.doi.org/10.1034/j.1600-0447.2001.1040s2041.x

[6] Johnson, S., Zinkler, M. and Priebe, S. (2001) Mental Health Service Provision in England. Acta Psychiatrica Scandinavica Supplementum, 104, 47-55. http://dx.doi.org/10.1034/j.1600-0447.2001.1040s2047.x

[7] Knapp, M., Beecham, J., McDaid, D., Matosevic, T. and Smith, M. (2011) The Economic Consequences of Deinstitutionalisation of Mental Health Services: Lessons from a Systematic Review of European Experience. Health \& Social Care in the Community, 19, 113-125.

[8] Chow, W.S. and Priebe, S. (2013) Understanding Psychiatric Institutionalization: A Conceptual Review. BMC Psychiatry, 13, 169-182. http://dx.doi.org/10.1186/1471-244X-13-169

[9] Xie, H. (2013) Strengths-Based Approach for Mental Health Recovery. Iranian Journal of Psychiatry and Behavioral Sciences, 7, 5-10. http://www.ncbi.nlm.nih.gov/pmc/articles/PMC3939995/

[10] Fukui, S., Goscha, R., Rapp, C.A., Mabry, A., Liddy, P. and Marty, D. (2012) Strengths Model Case Management Fidelity Scores and Client Outcomes. Psychiatric Services, 63, 708-810. http://dx.doi.org/10.1176/appi.ps.201100373

[11] Farkas, M. (2007) The Vision of Recovery Today: What It Is and What It Means for Services. World Psychiatry, 6, 6874. http://www.ncbi.nlm.nih.gov/pmc/articles/PMC2219905/

[12] Ibrahim, N., Michail, M. and Callaghan, P. (2014) The Strengths Based Approach as a Service Delivery Model for Severe Mental Illness: A Meta-Analysis of Clinical Trials. BMC Psychiatry, 14, 243. http://dx.doi.org/10.1186/s12888-014-0243-6

[13] OECD iLibrary (2014) Psychiatric Care Beds per 1000 Population. http://www.oecd-ilibrary.org/social-issues-migration-health/psychiatric-care-beds psycarebed-table-en/ 
[14] Ito, H. and Sederer, L.I. (1999) Mental Health Services Reform in Japan. Harvard Review of Psychiatry, 7, $208-215$. http://dx.doi.org/10.3109/hrp.7.4.208

[15] Ito, H., Frank, R.G., Nakatani, Y. and Fukuda, Y. (2013) Mental Health Care Reforms in Asia: The Regional Health Care Strategic Plan: The Growing Impact of Mental Disorders in Japan. Psychiatric Services, 64, 617-619. http://dx.doi.org/10.1176/appi.ps.201200518

[16] Japan Ministry of Health, Labour and Welfare (2004) A Visions for Reform of the Mental Health Care System. (In Japanese) http://www.mhlw.go.jp/topics/2004/09/tp0902-1.html

[17] Japan Ministry of Health, Labour and Welfare (2009) Committee Report on Future Mental Health and Welfare. (In Japanese) http://www.mhlw.go.jp/shingi/2009/09/s0924-2.html

[18] Shiina, A., Iyo, M., Yoshizumi, A. and Hirabayashi, N. (2014) Recognition of Change in the Reform of Forensic Mental Health by Clinical Practitioners: A Questionnaire Survey in Japan. Annals of General Psychiatry, 13, 9. http://dx.doi.org/10.1186/1744-859X-13-9

[19] Nakatani, Y. (2012) Challenges in Interfacing between Forensic and General Mental Health: A Japanese Perspective. International Journal of Law and Psychiatry, 35, 406-411. http://dx.doi.org/10.1016/j.ijlp.2012.09.021

[20] Japan Ministry of Health, Labour and Welfare (2010) Total Site of Mental Health. (In Japanese) http://www.mhlw.go.jp/kokoro/speciality/data.html

[21] Kunitoh, N. (2013) From Hospital to the Community: The Influence of Deinstitutionalization on Discharged Long-Stay Psychiatric Patients. Psychiatry and Clinical Neurosciences, 67, 384-396. http://dx.doi.org/10.1111/pcn.12071

[22] Schulz, R., Girard, C. and Harrison, S. (1990) Management Practices and Priorities for Mental Health System Performance: Evidence from England and West Germany. The International Journal of Health Planning and Management, 5, 135-146. http://dx.doi.org/10.1002/hpm.4740050206

[23] Peplau, H. (1952) Interpersonal Relations in Nursing: A Conceptual Frame of Reference for Psychodynamic Nursing. G. P. Putnam's Sons, New York.

[24] Carpenito-Moyet, L.J. (2008) Handbook of Nursing Diagnosis. 12th Edition, Lippincott Williams and Wilkins, Philadelphia.

[25] Schultz, J.M. and Videbeck, S.L. (2009) Lippincott’s Manual of Psychiatric Nursing Care Plans. Vol. 19, Lippincott Williams and Wilkins, Philadelphia.

[26] Stuart, G.W. and Laraia, M.T. (2005) Principles and Practice of Psychiatric Nursing. Vol. 247, 8th Edition, Elsevier Mosby, St Louis.

[27] Gottlieb, L.N., Gottlieb, B. and Shamian, J. (2012) Principles of Strengths-Based Nursing Leadership for StrengthsBased nursing CARE: A New Paradigm for Nursing and Healthcare for the 21st Century. Nursing Leadership, 25, 3850. http://dx.doi.org/10.12927/cjnl.2012.22960

[28] Lundman, B., Aléx, L., Jonsén, E., Norberg, A., Nygren, B., Santamäki Fischer, R and Strandberg, G. (2010) Inner Strength-A Theoretical Analysis of Salutogenic Concepts. International Journal of Nursing Studies, 47, 251-260. http://dx.doi.org/10.1016/j.ijnurstu.2009.05.020

[29] Antonovsky, A. (1979) Health, Stress and Coping. Jossey-Bass Publishers, San Francisco.

[30] Lundman, B., Viglund, K., Aléx, L., Jonsén, E., Norberg, A., Fischer, R.S., Strandberg, G. and Nygren, B. (2011) Development and Psychometric Properties of the Inner Strength Scale. International Journal of Nursing Studies, 48, 1266-1274. http://dx.doi.org/10.1016/j.ijnurstu.2011.03.006

[31] Lundman, B., Aléx, L., Jonsén, E., Lövheim, H., Nygren, B., Santamäki Fischer, R., Strandberg, G. and Norberg, A. (2012) Inner Strength in Relation to Functional Status, Disease, Living Arrangements, and Social Relationships among People Aged 85 Years and Older. Geriatric Nursing, 33, 167-176. http://dx.doi.org/10.1016/j.gerinurse.2011.11.001

[32] Viglund, K., Jonsén, E., Strandberg, G., Lundman, B. and Nygren, B. (2013) Inner Strength as a Mediator of the Relationship between Disease and Self-Rated Health among Old People. Journal of Advanced Nursing, 70, 144-152. http://dx.doi.org/10.1111/jan.12179

[33] Boman, E., Gustafson, Y., Häggblom, A., Santamäki Fischer, R. and Nygren, B. (2014) Inner Strength—Associated with Reduced Prevalence of Depression among Older Women. Aging \& Mental Health, 17, 1-6. http://dx.doi.org/10.1080/13607863.2014.977775

[34] Iwamoto, M. and Fujita, S. (2013) A Concept Analysis of Strengths: Practical Use of Concept to the Cancer Survivors. Journal of Kochi Women's University Academy of Nursing, 38, 12-21. (In Japanese)

[35] Okahisa, R. and Tada, T. (2014) Development of a Strengths Measurement Scale for the Lifestyle Transformation Process. Journal of Medical Investigation, 61, 84-93. http://dx.doi.org/10.2152/jmi.61.84

[36] Okahisa, R. and Tada, T. (2014) The Strengths of Women in the Process of Life Style Transformation. Journal of Nursing Investigation, 12, 50-59. (In Japanese) 
[37] Fukuoka, K. and Azechi, H. (2012) Nursing Intervention to Improve Strengths for Person with Eating Disorder. Journal of Kochi Women's University Academy of Nursing, 38, 61-67. (In Japanese)

[38] Uehara, K., Ikeda, A. and Toyama, F. (2014) Changes in Nurses' Perception of Patients in Acute Psychiatric Wards through Case Review Meetings Focused on “Strong Point” of Patient. Journal Okinawa Prefectural College of Nursing, 15, 33-42. (In Japanese)

[39] Rapp, C.A. and Goscha, R.J. (2006) The Strengths Model Case Management with Psychiatric Disabilities. 2nd Edition, Oxford University Press, Oxford.

[40] Takahashi, K., Kataoka, M., Nagase, Y., Ieda, S., Kouketu, T. and Muraoka, H. (2006) Nurse Caring Behaviors and Task for Community Reintegration Training of Long-Termed Hospitalized Mentally Ill Patients: Viewed in an Official Position. Journal of Gifu College of Nursing, 7, 11-19. (In Japanese)

[41] Tanioka, T., Kataoka, M., Yasuhara, Y., Miyagawa, M. and Ueta, I. (2011) The Role of Nurse Administrators and Managers in Quality Psychiatric care. Journal of Medical Investigation, 58, 1-10. http://doi.org/10.2152/jmi.58.1

[42] Japan Ministry of Health, Labour and Welfare (2001) Guidelines about the Administration of the Nurses' School. http://kouseikyoku.mhlw.go.jp/kantoshinetsu/shokan/kankeihourei/documents/yoryo_kango_shido.pdf

[43] Rapp, C., Saleebey, D. and Sullivan, W.P. (2006) The Future of Strengths-Based Social Work. In: Daley, J.G., Ed., Advances in Social Work: Special Issue on the Futures of Social Work, Trafford Publishing, Indianapolis, 81-90. 